\title{
Pricing and inventory control policy for non-instantaneous deteriorating items with time- and price-dependent demand and partial backlogging
}

\author{
Hiwa Farughi ${ }^{a^{*}}$, Narges Khanlarzade ${ }^{b}$ and Babak Yousefi Yegane ${ }^{c}$
}

${ }^{a}$ Assistant Professor of Industrial Engineering, Faculty of Engineering, University of Kurdistan, Iran

${ }^{b}$ MS.c graduate of Industrial Engineering, Tarbiat Modares University

${ }^{c}$ Department of Industrial Engineering, Islamic Azad University, Malayer Branch, Malayer, Iran

\section{H R O N I C L E A B T R A C T}

Article history:

Received October 15, 2013

Received in revised format

March 62014

Accepted March 24, 2014

Available online

March 262014

Keywords:

Pricing

Inventory control

Partial backlogging

Perishable items
Determining the optimal inventory control and selling price for deteriorating items is of great significance. In this paper, a joint pricing and inventory control model for deteriorating items with price- and time-dependent demand rate and time-dependent deteriorating rate with partial backlogging is considered. The objective is to determine the optimal price, the replenishment time, and economic order quantity such that the total profit per unit time is maximized. After modeling the problem, an algorithm is proposed to solve the resulted problem. We also prove that the problem statement is concave function and the optimal solution is indeed global.

\section{Introduction}

Nowadays, most business units are faced with increasingly volatile business environments, characterized by shorter product life cycles and more rapid technological developments. In order to obtain competitive margins, new products must be introduced into the market, frequently. In this case, life cycles of old and new products overlap and they coexist in a considerable period of time (Chew et al., 2014). Deterioration can be defined as the loss of marginal value of commodity, which yields in decreased usefulness. Under this definition, many goods such as clothing and electronic devices can be considered as perishable items. Today, competition in the market has led all the competitors to increase the quality of their products, so a producer's success is determined by the price of his/her products. Pricing and inventory control policy are two important factors for the success of business owners. In recent years, many researchers have studied the pricing and inventory control issues simultaneously for deteriorating items. Most physical goods such as drugs, vegetables deteriorate over time (Wee, 1993). Pricing and inventory control of deteriorating items have been

* Corresponding author. Tel: +989188736075

E-mail addresses: $\underline{h . f a r u g h i @ u o k . a c . i r}$ (H. Farughi)

C 2014 Growing Science Ltd. All rights reserved. doi: $10.5267 /$ j.ds1.2014.3.005 
extensively studied by many researchers. Deteriorating inventory analysis began with the work of Ghare and Schrader (1963), who established the classical no-shortage inventory model with a constant rate of decay. However, it has been empirically observed that failure and life expectancy of many items can be expressed in Weibull distribution items. This empirical observation has prompted researchers to present the products' deterioration time by Weibull distribution. Covert and Philip (1973) extended Ghare and Schrader's model and obtained an economic order quantity model for variable rate of deterioration by assuming a two-parameter Weibull distribution. Researchers such as Philip (1974), Misra (1975), Tadikamalla (1978), Wee (1997), Chakrabarty et al. (1998), and Mukhopadhyay et al. (2004) developed economic order quantity models by concentrating on this type of products. Abad (1996) considered a pricing and lot sizing problem for a product with variable rate of deterioration and partial backlogging. Aggarwal and Jaggi (1995) explored the ordering policy for deteriorating items under permissible delay in payments. Hwang and Shinn (1997) dealt with pricing and lot sizing decisions for exponentially deteriorating products, with also permissible delay in payments. Jamal et al. (1997) generalized Aggarwal and Jaggi's model to allow for shortages. Chang and Dye (2001) extended Jamal et al.'s model. Chang et al. (2002) considered the linear demand for deteriorating items over time and partial backlogging rate.

Chang et al. (2006) established an EOQ model for deteriorating items for a retailer to determine its optimal selling price and lot sizing policy with partial backlogging. Dye et al. (2007) presented a pricing and inventory policy for deteriorating items with shortage. Most studies assume that deterioration begins from the moment of a product's arrival in the stock. In fact, most of the goods are thought to have a quality maintenance or original condition span in which no deterioration occurs. In the real world, this phenomenon exists commonly among goods such as fresh fruits and vegetables. $\mathrm{Wu}$ et al. (2006) defined the non-instantaneous phenomenon and developed a replenishment policy for non-instantaneous deteriorating items with stock-dependent demand to minimize the total inventory cost per unit time.

Geetha and Uthayakumar (2010) proposed an EOQ-based model for non-instantaneous deteriorating items with permissible delay in payments. In this model, demand and price are constant and shortages are allowed and are partially backlogged. Cai et al. (2011) studied pricing and ordering policy problems in two-stage supply chains by considering the partial lost sales based on the game theory. Musa and Sani (2012) developed a mathematical model for inventory control of non-instantaneous deteriorating items with permissible delay in payments. Maihami and Nakhai (2012) developed a mathematical model for joint pricing and inventory control of non-instantaneous deteriorating item with partial backlogging, the unsatisfied demand being backlogged and the fraction of shortage backordered considered as $\beta(x)=k_{0} e^{-\delta x}$. Avinadav et al. (2013) employed a price-and timedependent function and developed a mathematical model to calculate the optimal price, the order quantity and the replenishment period for perishable items.

Pricing is a major strategy for a seller to achieve the maximum profit. Consequently, in this paper, Maihami and Nakhai's proposed model is developed and a different backlogging function for unsatisfied demand and time-dependent deterioration rate is used. The rest of the paper is organized as follows. In section 2, we describe the assumption and notation employed throughout this study is described; therein, the mathematical model and the necessary considerations for finding an optimal solution are established. Furthermore, it is demonstrated that the total profit is a concave function of selling price when the replenishment schedule is given. In section 3, we provide a simple algorithm to find the optimal replenishment schedule and selling price for the proposed model. In section 4, we use a numerical example to illustrate the algorithm. Finally, we make a summary and provide some suggestions for future research in section 5 . 


\section{Assumptions and notations}

\subsection{Assumptions}

The mathematical model is based on the following assumptions:

1. The mathematical model is proposed for a non-instantaneous deterioration item.

2. The lead time is zero.

3. The demand rate $D(t, p)=(a-b p) e^{\lambda t},(a>0, b>0)$ is a linearly decreasing function of the price and decreases (increases) exponentially with time when $\lambda<0(\lambda>0)$.

4. Shortages are allowed; only a fraction of the demand is assumed to be backlogged. Following Chang and Dye (1999) we take $\beta(x)=1 /(1+\delta x)(\delta>0)$; Note that if $\beta(x)=1$ (or 0$)$ for all $x$, and then the shortage is completely backlogged (or lost).

5. The on-hand inventory deteriorates at a rate $\theta$.

There is no replacement or repair of deteriorated items and they are withdrawn immediately from store.

\subsection{Notations}

$c \quad$ the constant purchasing cost per unit

$h \quad$ the holding cost per unit per unit time

$s \quad$ The backorder cost per unit per time

$o \quad$ The cost of lost sales per unit

$t_{d} \quad$ The length of time in which the product exhibit no deterioration

$t_{1} \quad$ The length of time in which there is no inventory shortage

$T \quad$ The length of replenishment cycle time

$Q \quad$ The order quantity

$P^{*} \quad$ The optimal selling price per unit

$t_{1}^{*} \quad$ The optimal length of time in which there is no inventory shortage

$T^{*} \quad$ The optimal length of replenishment cycle time

$Q^{*} \quad$ The optimal order quantity

$I_{l}(t) \quad$ the inventory level at time $t \in\left[0, t_{d}\right]$

$I_{2}(t) \quad$ the inventory level at time $t \in\left[t_{d}, t_{1}\right]$

$I_{3}(t) \quad$ the inventory level at time $t \in\left[t_{t}, T\right]$

$I_{0} \quad$ the maximum inventory level

$S \quad$ The maximum amount of demand backlogged

$T P\left(p, t_{1}, T\right) \quad$ The total profit per unit time of the inventory system

$T P^{*} \quad$ The optimal total profit per unit time of the inventory system 


\subsection{Mathematical formulation}

Based on the represented notations, the inventory level follows the pattern depicted in Fig.1. In order to establish the total profit function, the following time intervals are considered separately, $\left[0, t_{d}\right]$ the inventory level is assumed to decrease only by demand, the interval $\left[t_{d}, t_{1}\right]$ in which the inventory level is affected by both demand and deterioration and drops to zero and the interval $\left[t_{1}, T\right]$ where the shortage occurs. Hence, the inventory level is governed by the following differential equation during the first interval:

$\frac{d I_{1}(t)}{d t}=-D(p, t) \quad 0 \leq t \leq t_{d}$

With the boundary condition $I_{1}(0)=I_{0}$, solving the differential Eq. (1) for the inventory yields,

$I_{1}(t)=\frac{a-b p}{\lambda}\left(1-e^{\lambda t}\right)+I_{0} \quad 0 \leq t \leq t_{d}$

At the next interval $\left[t_{d}, t_{1}\right]$, the inventory level is affected by demand and deterioration simultaneously, so the inventory status can be presented by solving the equation below:

$\frac{d I_{2}(t)}{d t}+\theta I_{2}(t)=-D(p, t) \quad t_{d} \leq t \leq t_{1}$

and the boundary condition $I_{2}\left(t_{1}\right)=0$ the inventory level is follows,

$I_{2}(t)=\frac{a-b p}{\lambda+\theta} e^{-\theta t}\left[e^{(\lambda+\theta) t_{1}}-e^{(\lambda+\theta) t}\right] \quad t_{d} \leq t \leq t_{1}$

Considering the continuity of $I(t)$ at $t=t_{d}$, the maximum inventory level for each cycle is as follows,

$$
I_{0}=\frac{a-b p}{\lambda+\theta} e^{-\theta t_{d}}\left[e^{(\lambda+\theta) t_{1}}-e^{(\lambda+\theta) t_{d}}\right]-\frac{a-b p}{\lambda}\left[1-e^{\lambda t_{d}}\right]
$$

During the interval $\left[t_{1}, T\right]$, the inventory level only depends on demand, shortage occurred and demand is partially backlogged according to the fraction $\beta(T-t)$. That is, the inventory level at time $t$ is governed by the following differential equation:

$\frac{d I_{3}(t)}{d t}=-D(p, t) \beta(T-t)=\frac{D(p, t)}{1+\delta(T-t)} t_{1} \leq t \leq T$

With the condition $I_{3}\left(t_{1}\right)=0$ the solution of Eq. (6) is as follows,

$I_{3}(t)=-(a-b p) \int_{t_{1}}^{t} \frac{e^{-\lambda x}}{1+\delta(T-x)} d x=\frac{e^{\left(T+\frac{1}{\delta}\right)}}{\delta}\left[E i\left(t_{1}-T-\frac{1}{\delta}\right)-E i\left(t-T-\frac{1}{\delta}\right)\right] t_{1} \leq t \leq T$

where $E i(z)=\int_{1}^{\infty} \frac{e^{-z t}}{t^{n}} d t$. The maximum shortage is as follows,

$S S=-I_{3}(T)=\frac{e^{\left(T+\frac{1}{\delta}\right)}}{\delta}\left[E i\left(t_{1}-T-\frac{1}{\delta}\right)-E i\left(-\frac{1}{\delta}\right)\right]$ 


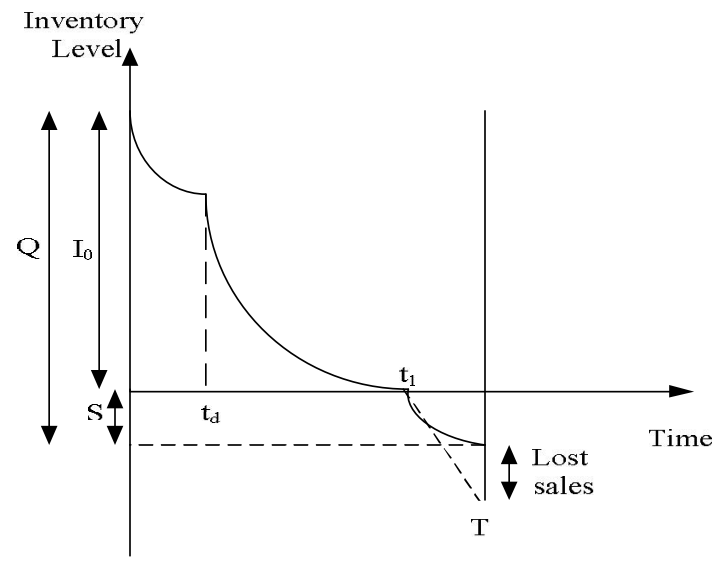

Fig. 1. Graphical representation of the inventory system

The order quantity per cycle is the sum of $I_{0}$ and $S S$, i.e.

$Q=I_{0}+S S=\frac{a-b p}{\lambda+\theta} e^{-\theta t_{d}}\left[e^{(\lambda+\theta) t_{1}}-e^{(\lambda+\theta) t_{d}}\right]-\frac{a-b p}{\lambda}\left[1-e^{\lambda t_{d}}\right]+\frac{e^{\left(T+\frac{1}{\delta}\right)}}{\delta}\left[E i\left(t_{1}-T-\frac{1}{\delta}\right)-E i\left(-\frac{1}{\delta}\right)\right]$

Next, the total relevant inventory cost per cycle consists of the following elements:

i. the ordering cost per cycle is $A$.

ii. The inventory holding cost that is denoted by $H C$ is given by

$$
H C=h\left[\int_{0}^{t_{d}} I_{1}(t) d t+\int_{t_{d}}^{t_{1}} I_{2}(t) d t\right]=h\left[\begin{array}{c}
\frac{(a-b p) e^{-\theta t_{d}}\left(\theta e^{(\lambda+\theta) t_{d}}+\lambda e^{(\lambda+\theta) t_{1}}-(\lambda+\theta) e^{\left(\lambda t_{1}+\theta t_{d}\right)}\right)}{\lambda \theta(\lambda+\theta)} \\
+\frac{(a-b p) e^{-\theta t_{d}}\left(\frac{-\left(\left(e^{-\theta t_{d}}\left(e^{\lambda t_{d}}-1\right)(\lambda+\theta)\right)\right.}{\lambda}+\theta t_{d} e^{(\lambda+\theta) t_{d}}+\lambda t_{d} e^{(\lambda+\theta) t_{1}}\right)}{\lambda(\lambda+\theta)}
\end{array}\right]
$$

iii. The shortage cost per cycle due to backlog that is denoted by $S C$ is given by

$$
S C=s \int_{t_{1}}^{T}\left[-I_{3}(t)\right] d t=s(a-b p) \frac{(a-b p)}{\delta^{2} \lambda}\left[\left(\delta e^{\lambda t_{1}}-\lambda e^{\left(T+\frac{1}{\delta}\right) \lambda}\left(\delta\left(t_{1}-T\right)-1\right) E i\left[\lambda\left(t_{1}-\left(T+\frac{1}{\delta}\right)\right)\right]\right)-\delta e^{\lambda T}+\lambda e^{\left(T+\frac{1}{\delta}\right) \lambda} E i\left(-\frac{1}{\delta}\right)\right]
$$

iv. The opportunity cost due to lost sales which is denoted by $O C$ is given by

$$
O C=o \int_{t_{1}}^{T} D(p, t)(1-\beta(T-t)) d t=o(a-b p)\left[\left(\frac{e^{\lambda T}}{\lambda}+\frac{e^{\left(T+\frac{1}{\delta}\right)} E i\left[-\frac{1}{\delta}\right]}{\delta}\right)-\left(\frac{e^{\lambda t_{1}}}{\lambda}+\frac{e^{\left(T+\frac{1}{\delta}\right)} E i\left[\left(t_{1}-T-\frac{1}{\delta}\right) \lambda\right]}{\delta}\right)\right]
$$

v. the purchase cost per cycle is as follows,

$$
P C=C Q=C\left[\frac{a-b p}{\lambda+\theta}\left(e^{(\lambda+\theta) t_{1}}-1\right)+\frac{e^{\left(T+\frac{1}{\delta}\right)}}{\delta}\left[E i\left(t_{1}-T-\frac{1}{\delta}\right)-E i\left(-\frac{1}{\delta}\right)\right]\right]
$$

vi. $S R$ : The sales revenue

$$
S R=\frac{e^{\lambda t_{1}}-1}{\lambda}(a-b p) p+p\left(\frac{e^{\left(T+\frac{1}{\delta}\right)}}{\delta}\left(E i\left(t_{1}-T-\frac{1}{\delta}\right)-E i\left(-\frac{1}{\delta}\right)\right)\right)
$$


Therefore, the total profit per unit time of proposed model is obtained as follows,

$\boldsymbol{T P}\left(\boldsymbol{p}, \boldsymbol{t}_{\mathbf{1}}, \boldsymbol{T}\right)=\frac{1}{T}$ (Sales Revenue - ordering cost - purchace cost - shortage cost - opportunity cost - inventory holding cost $)$

$T P_{\left(p, t_{1}, T\right)}$ is function of $t_{1}, T, p$; so for any given $p$ The necessary conditions for the total relevant profit per unit time to be maximized are $\frac{\partial T P\left(p, t_{1}, T\right)}{\partial t_{1}}=0$ and $\frac{\partial T P\left(p, t_{1}, T\right)}{\partial T}=0$ simultaneously. That is:

$$
\begin{aligned}
& \frac{\partial T P\left(p, t_{1}, T\right)}{\partial t_{1}}= \\
& \frac{e^{\lambda t_{1}} p(a-b p)}{T}+\frac{e^{t_{1}} p}{\delta\left(-T-\frac{1}{\delta}+t_{1}\right)}-C\left(e^{(\theta+\lambda) t_{1}}(a-b p)+\frac{e^{t_{1}}}{\delta\left(-T-\frac{1}{\delta}+t_{1}\right)}\right)-o(a-b p)\left(-e^{\lambda t_{1}}-\frac{e^{\lambda\left(t_{1}\right)}}{\delta\left(-T-\frac{1}{\delta}+t_{1}\right)}\right)- \\
& \frac{(a-b p)^{2} s\left(e^{\lambda t_{1}} \delta \lambda-e^{\left(T+\frac{1}{\delta}\right) \lambda} \delta \lambda \mathrm{Ei}\left[\lambda\left(-T-\frac{1}{\delta}+t_{1}\right)\right]-\frac{\lambda}{\delta} e^{\lambda t_{1}}\right)}{\delta^{2} \lambda}-h\left(\frac{e^{-\theta t_{d}}(a-b p)\left(e^{(\theta+\lambda) t_{1}} \lambda(\theta+\lambda)-e^{\lambda t_{1}+\theta t_{d}} \lambda(\theta+\lambda)\right)}{\theta \lambda(\theta+\lambda)}-e^{(\theta+\lambda) t_{1}-\theta t_{d}}(a-b p) t_{d}\right) \\
& \frac{\boldsymbol{\partial T} \boldsymbol{P}\left(\boldsymbol{p}, \boldsymbol{t}_{1}, \boldsymbol{T}\right)}{\boldsymbol{\partial} \boldsymbol{T}}=-\frac{\left(-1+e^{\lambda t_{1}}\right) p(a-b p)}{T^{2} \lambda}+\frac{e^{T+\frac{1}{\delta} p\left(-\mathrm{Ei}\left[-\frac{1}{\delta}\right]+\mathrm{Ei}\left[-T-\frac{1}{\delta}+t_{1}\right]\right)}}{\delta}-\frac{e^{t_{1} p}}{\delta\left(-T-\frac{1}{\delta}+t_{1}\right)}-C\left(\frac{e^{T+\frac{1}{\delta}\left(-\mathrm{Ei}\left[-\frac{1}{\delta}\right]+\mathrm{Ei}\left[-T-\frac{1}{\delta}+t_{1}\right]\right)}}{\delta}-\frac{e^{t_{1}}}{\delta\left(-T-\frac{1}{\delta}+t_{1}\right)}\right)- \\
& o(a-b p)\left(e^{T \lambda}+\frac{e^{\left(T+\frac{1}{\delta}\right) \lambda} \lambda \operatorname{Ei}\left[-\frac{\lambda}{\delta}\right]}{\delta}-\frac{e^{\left(T+\frac{1}{\delta}\right) \lambda} \lambda \operatorname{Ei}\left[\lambda\left(-T-\frac{1}{\delta}+t_{1}\right)\right]}{\delta}+\frac{e^{\left(T+\frac{1}{\delta}\right) \lambda+\lambda\left(-T-\frac{1}{\delta}+t_{1}\right)}}{\delta\left(-T-\frac{1}{\delta}+t_{1}\right)}\right)- \\
& \frac{\left\{(a-b p)^{2} S\left(-e^{T \lambda} \delta \lambda-e^{\left(T+\frac{1}{\delta}\right) \lambda} \lambda^{2} \operatorname{Ei}\left[-\frac{\lambda}{\delta}\right]+e^{\left(T+\frac{1}{\delta}\right) \lambda} \delta \lambda \operatorname{Ei}\left[\lambda\left(-T-\frac{1}{\delta}+t_{1}\right)\right]-e^{\left(T+\frac{1}{\delta}\right) \lambda} \lambda^{2} \operatorname{Ei}\left[\lambda\left(-T-\frac{1}{\delta}+t_{1}\right)\right]\left(-1+\delta\left(-T+t_{1}\right)\right)+\frac{e^{\left(T+\frac{1}{\delta}\right) \lambda+\lambda\left(-T-\frac{1}{\delta}+t_{1}\right)} \lambda\left(-1+\delta\left(-T+t_{1}\right)\right)}{-T-\frac{1}{\delta}+t_{1}}\right)\right\}}{\delta^{2} \lambda}
\end{aligned}
$$

\section{Theorem 1.}

(a) The system of (16) and (17) has a unique solution.

(b) The solution in (a) satisfies the second-order conditions for maximization.

Proof. See Appendix A for details.

Solving the Eq. (16) and Eq. (17), the optimum value for $T^{*}$ and $t_{1}^{*}$ is obtained, so the selling price can be determined from the Eq. (18). For this purpose, it is sufficient to solve the following equation:

$$
\begin{aligned}
& \frac{\partial T P\left(\boldsymbol{p}, \boldsymbol{t}_{\mathbf{1}}^{*}, \boldsymbol{T}^{*}\right)}{\partial \boldsymbol{p}}=\frac{b\left(-1+e^{\lambda t^{*}} 1\right) p}{T^{*} \lambda}+\frac{\left(-1+e^{\lambda t^{*}}{ }_{1}\right)(a-b p)}{T^{*} \lambda}+\frac{b C\left(-1+e^{\left.(\theta+\lambda) t^{*} 1\right)}\right.}{\theta+\lambda}+\frac{e^{T^{*}+\frac{1}{\delta}\left(-\operatorname{Ei}\left[-\frac{1}{\delta}\right]+\operatorname{Ei}\left[-T-\frac{1}{\delta}+t^{*} 1\right]\right)}}{\delta}+ \\
& b o\left(\frac{e^{T^{*} \lambda}}{\lambda}-\frac{e^{\lambda t^{*}} 1}{\lambda}+\frac{e^{\left(T^{*}+\frac{1}{\delta}\right) \lambda} \operatorname{Ei}\left[-\frac{\lambda}{\delta}\right]}{\delta}-\frac{e^{\left(T^{*}+\frac{1}{\delta}\right) \lambda} \operatorname{Ei}\left[\lambda\left(-T^{*}-\frac{1}{\delta}+t^{*} 1\right)\right]}{\delta}\right)+\frac{\left\{2 b(a-b p) s\left(-e^{T^{*} \lambda} \delta+e^{\lambda t^{*}} 1 \delta-e^{\left(T^{*}+\frac{1}{\delta}\right) \lambda} \lambda \operatorname{Ei}\left[-\frac{\lambda}{\delta}\right]-e^{\left(T^{*}+\frac{1}{\delta}\right) \lambda} \lambda \operatorname{Ei}\left[\lambda\left(-T^{*}-\frac{1}{\delta}+t^{*}{ }_{1}\right)\right]\left(-1+\delta\left(-T^{*}+t^{*} 1\right)\right)\right)\right\}}{\delta^{2} \lambda}-
\end{aligned}
$$

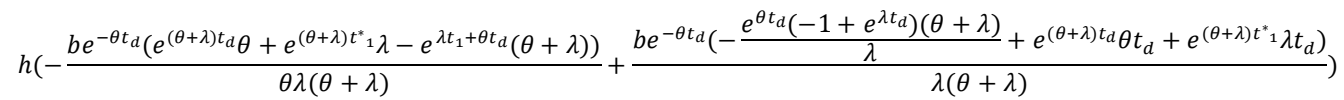

The second order derivation of $T P_{\left(P, t_{1}^{*}, T^{*}\right)}$ with respect to $P$ is given by the following equation:

$$
\frac{\boldsymbol{\partial}^{2} \boldsymbol{T} \boldsymbol{P}\left(\boldsymbol{p}, \boldsymbol{t}_{1}^{*}, \boldsymbol{T}^{*}\right)}{\boldsymbol{\partial} \boldsymbol{p}^{2}}=-\frac{2 b\left(-1+e^{\lambda t_{1}}\right)}{T \lambda}-\frac{2 b^{2} s\left(-e^{T \lambda} \delta+e^{\lambda t_{1}} \delta-e^{\left(T+\frac{1}{\delta}\right) \lambda} \lambda \operatorname{Ei}\left[-\frac{\lambda}{\delta}\right]-e^{\left(T+{ }_{\delta}^{1}\right) \lambda} \lambda \operatorname{Ei}\left[\lambda\left(-T-\frac{1}{\delta}+t_{1}\right)\right]\left(-1+\delta\left(-T+t_{1}\right)\right)\right)}{\delta^{2} \lambda}<0
$$

\section{The algorithm}

We propose a simple algorithm to obtain the optimal solution of the problem.

Step 1. Start with $\mathrm{j}=0$ and the initial value of $p_{j}=p_{1}$.

Step 2. Find the optimal value of $T^{*}$ and $t^{*}$ for a given price $p_{j}$.

Step 3. Use the result in step 2 and then determine the optimal $p_{j+1}$ by Eq. (18).

Step 4. If the difference between $p_{j}$ and $p_{j+1}$ is sufficiently small, set $p^{*}=p_{j+1}$, otherwise set $j=j+1$ and go to step 2 . 
By using above algorithm, we obtain the optimal solution $p^{*}, t_{1}^{*}, T^{*}$, we can obtain $T P^{*}$ using Eq. (15).

\section{Numerical example}

To illustrate the solution procedure, we solve the following numerical example; the results can be obtained by applying the Mathematica 8.0 .

\subsection{Example.}

We adopt the same example of Maihami and Nakhai (2012) to see the optimal inventory control policy and optimal selling price. The example is based on the following parameters and functions:

$A=\$ 250 /$ perorder,$C=\$ 200 /$ perunit,$h=\$ 40 /$ perunittime, $s c=\$ 80 /$ perunit $/$ pertime,

$o c=\$ 120 /$ perunit $, \theta=0.08, t_{d}=0.04 D(t, p)=(500-0.5 p) e^{-0.98 t}, \beta(x)=\frac{1}{1+0.2 x}$

First we set $p_{1}=\frac{a+b c}{2 b}$, after five iteration we have $p^{*}=1880.64, t_{1}^{*}=0.06321, T^{*}=0.08547$ $T P^{*}=9.64617 \times 10^{6}$. Fig. 2 . shows that $T P^{*}$ is strictly concave in $p$.

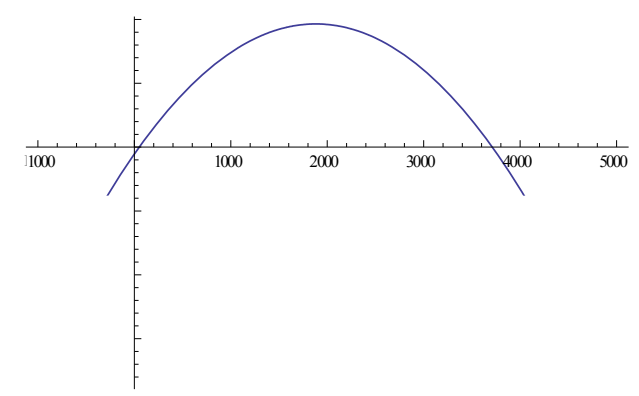

Fig. 2. Graphical representation of $T P\left(p \mid t_{1}^{*}, T^{*}\right)$

\section{Sensitivity analysis}

In this section, we focus on the effects of changes in the parameters of the system on $p^{*}, t_{1}^{*}, T^{*}$, and $T P^{*}$. The sensitive analysis is performed by changing each value of the parameters by $+50 \%,+25 \%$, $25 \%$ and $-50 \%$, taking one parameter at a time end keeping the remaining parameter values unchanged. The computational results are shown in Table 1.

The sensitive analysis shown in Table 1 indicates the following observations:

1- When the value of parameters increases, the optimal selling rate will increase. $p^{*}$ is too much positively sensitive to change in parameter $c$. This result is reasonable because the purchase cost has a strong and positive effect on the optimal selling rate.

2- When the values of $A, s$, and $o$ increase, the optimal value of $t_{1}^{*}$ increases and it decreases as the value parameters $h$ and $\theta$ increase.

3- When the value of parameter $A$ increases, the optimal length of $T^{*}$ increases and as the values of parameters $h, s, o$, and $\theta$ increases, it would decrease.

4- When the values of all the above parameters increase, the optimal profit per unit time will decrease; this implies that the increase in costs and deterioration rate have a negative effect on the total profit per unit time. 
Table 1

Sensitive analysis with respect to the model parameters

\begin{tabular}{|c|c|c|c|c|c|}
\hline Parameter & Value & $p^{*}$ & $t_{1}^{*}$ & $T^{*}$ & $T P^{*}$ \\
\hline \multirow{4}{*}{$A$} & 125 & 1873.00 & 0.05182 & 0.06732 & $9.62021 \times 10^{6}$ \\
\hline & 188 & 1876.16 & 0.05687 & 0.07341 & $9.61300 \times 10^{6}$ \\
\hline & 313 & 1886.38 & 0.06601 & 0.08796 & $9.57023 \times 10^{6}$ \\
\hline & 375 & 1891.07 & 0.06936 & 0.08984 & $9.21869 \times 10^{6}$ \\
\hline \multirow{4}{*}{$c$} & 100 & 1842.82 & 0.07401 & 0.08162 & $9.97000 \times 10^{6}$ \\
\hline & 150 & 1861.24 & 0.06872 & 0.08221 & $9.86203 \times 10^{6}$ \\
\hline & 250 & 1908.00 & 0.06767 & 0.08602 & $9.20153 \times 10^{6}$ \\
\hline & 300 & 1937.21 & 0.07337 & 0.08917 & $9.00205 \times 10^{6}$ \\
\hline \multirow{4}{*}{$h$} & 20 & 1877.53 & 0.07901 & 0.08392 & $9.67899 \times 10^{6}$ \\
\hline & 30 & 1881.05 & 0.07464 & 0.08016 & $9.64865 \times 10^{6}$ \\
\hline & 50 & 1884.61 & 0.07258 & 0.07936 & $9.62001 \times 10^{6}$ \\
\hline & 60 & 1885.04 & 0.07209 & 0.07786 & $9.61054 \times 10^{6}$ \\
\hline \multirow{4}{*}{$S$} & 40 & 1878.59 & 0.06723 & 0.08429 & $9.66253 \times 10^{6}$ \\
\hline & 60 & 1880.00 & 0.06907 & 0.08391 & $9.65713 \times 10^{6}$ \\
\hline & 100 & 1881.04 & 0.07045 & 0.07975 & $9.63190 \times 10^{6}$ \\
\hline & 120 & 1883.19 & 0.07100 & 0.07816 & $9.61732 \times 10^{6}$ \\
\hline \multirow{4}{*}{$O$} & 60 & 1880.35 & 0.06509 & 0.08625 & $9.66631 \times 10^{6}$ \\
\hline & 90 & 1880.51 & 0.06896 & 0.08390 & $9.65163 \times 10^{6}$ \\
\hline & 150 & 1881.01 & 0.06973 & 0.08238 & $9.64502 \times 10^{6}$ \\
\hline & 180 & 1881.11 & 0.07013 & 0.08547 & $9.64265 \times 10^{6}$ \\
\hline \multirow{4}{*}{$\theta$} & 0.04 & 1878.28 & 0.07901 & 0.08982 & $9.67953 \times 10^{6}$ \\
\hline & 0.06 & 1879.86 & 0.07316 & 0.08801 & $9.66385 \times 10^{6}$ \\
\hline & 0.1 & 1882.32 & 0.06016 & 0.08391 & $9.63509 \times 10^{6}$ \\
\hline & 0.12 & 1883.36 & 0.05736 & 0.08072 & $9.629876 \times 10^{6}$ \\
\hline
\end{tabular}

\section{Conclusion}

In this paper, an appropriate model for a retailer to determine its optimal selling price and replenishment schedule for deteriorating item has been established. The demand is deterministic and depend on time and price, simultaneously. In addition, shortage is allowed and can be partially backlogged, where the backlogging rate is variable and dependent on the time of waiting for the next replenishment. In this study, some useful theorems, which characterize the optimal solution have been mentioned and an algorithm has been presented for determining the optimal price and optimal inventory control parameters. Finally, a numerical example is provided to illustrate the algorithm and solution procedure.

\section{Appendix A}

(a) Because of high complication in Eqs. (15) and (16), a straightforward proof does not exist. So, we only explain the proof procedure. First we must obtain $t_{1}($ or $T)$ based on $T\left(\right.$ or $\left.t_{1}\right)$ from Eq. (15) and Eq. (18), ( call this function $F(x)$ ). For $F(x)$, we take the first-order derivative with respect to $x$ and show that $F(x)$ is a strictly decreasing or increasing function. Next we use the intermediate value theorem and complete the proof. A simple and similar proof can be found in Yang et al. (2009).

(b) Let $\left(t_{1}^{*}, T^{*}\right)$ be the solution of Eq.(15) and Eq. (16), we obtain

$$
\frac{\partial T P_{\left(P, t_{1}, T\right)}}{\partial t_{1}^{2}}=\left[\frac{e^{\lambda t_{1}} p(a-b p) \lambda}{T}\right]-\left[e^{t_{1}} p\left(\frac{1}{\delta\left(T+\frac{1}{\delta}-t_{1}\right)^{2}}+\frac{1}{\delta\left(T+\frac{1}{\delta}-t_{1}\right)}\right)\right]-\left[C\left(e^{(\theta+\lambda) t_{1}}(a-b p)(\theta+\lambda)-e^{t_{1}}\left[\frac{1}{\delta\left(T+\frac{1}{\delta}-t_{1}\right)^{2}}+\frac{1}{\delta\left(T+\frac{1}{\delta}-t_{1}\right)}\right]\right)\right]+
$$




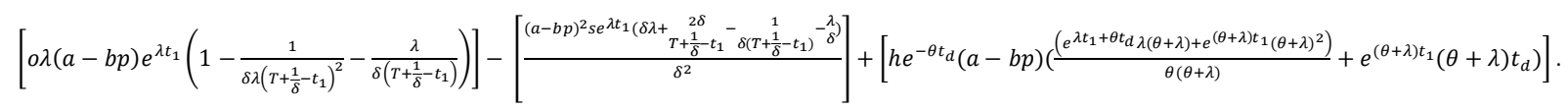

By assuming $\lambda<0,|\lambda|>\theta,|\lambda|>\delta, b p<a$, we have $\frac{\partial T P_{\left(P, t_{1}^{*}, T^{*}\right)}}{\partial t_{1}^{2}}<0$, because the first, second, fourth, and fifth brackets are always negative, and the summation of these brackets is greater than the third bracket.

$$
\begin{aligned}
& \frac{\partial T P_{\left(P, t_{1}, T\right)}}{\partial T^{2}}= \\
& \frac{2\left(-1+e^{\lambda t_{1}}\right) p(a-b p)}{T^{3} \lambda}+\frac{e^{T+\frac{1}{\delta}} p\left(-\mathrm{Ei}\left[-\frac{1}{\delta}\right]+\mathrm{Ei}\left[-T-\frac{1}{\delta}+t_{1}\right]\right)}{\delta}-\frac{e^{t_{1}} p}{\delta\left(-T-\frac{1}{\delta}+t_{1}\right)^{2}}-\frac{e^{t_{1}} p}{\delta\left(-T-\frac{1}{\delta}+t_{1}\right)}-C\left(\frac{e^{T+\frac{1}{\delta}\left(-\operatorname{Ei}\left[-\frac{1}{\delta}\right]+\operatorname{Ei}\left[-T-\frac{1}{\delta}+t_{1}\right]\right)}}{\delta}-\right. \\
& \left.\frac{e^{t_{1}}}{\delta\left(-T-\frac{1}{\delta}+t_{1}\right)^{2}}-\frac{e^{t_{1}}}{\delta\left(-T-\frac{1}{\delta}+t_{1}\right)}\right)-o(a-b p)\left(e^{T \lambda} \lambda+\frac{e^{\left(T+\frac{1}{\delta}\right) \lambda} \lambda^{2} \operatorname{Ei}\left[-\frac{\lambda}{\delta}\right]}{\delta}-\frac{e^{\left(T+\frac{1}{\delta}\right) \lambda} \lambda^{2} \operatorname{Ei}\left[\lambda\left(-T-\frac{1}{\delta}+t_{1}\right)\right]}{\delta}+\frac{e^{\left(T+\frac{1}{\delta}\right) \lambda+\lambda\left(-T-\frac{1}{\delta}+t_{1}\right)}}{\delta\left(-T-\frac{1}{\delta}+t_{1}\right)^{2}}+\right. \\
& \left.\frac{e^{\left(T+\frac{1}{\delta}\right) \lambda+\lambda\left(-T-\frac{1}{\delta}+t_{1}\right)} \lambda}{\delta\left(-T-\frac{1}{\delta}+t_{1}\right)}\right)-\frac{1}{\delta^{2} \lambda}(a-b p)^{2} s\left(-e^{T \lambda} \delta \lambda^{2}-e^{\left(T+\frac{1}{\delta}\right) \lambda} \lambda^{3} \operatorname{Ei}\left[-\frac{\lambda}{\delta}\right]+2 e^{\left(T+\frac{1}{\delta}\right) \lambda} \delta \lambda^{2} \operatorname{Ei}\left[\lambda\left(-T-\frac{1}{\delta}+t_{1}\right)\right]-\right. \\
& \frac{2 e^{\left(T+\frac{1}{\delta}\right) \lambda+\lambda\left(-T-\frac{1}{\delta}+t_{1}\right)} \delta \lambda}{-T-\frac{1}{\delta}+t_{1}}-e^{\left(T+\frac{1}{\delta}\right) \lambda} \lambda^{3} \operatorname{Ei}\left[\lambda\left(-T-\frac{1}{\delta}+t_{1}\right)\right]\left(-1+\delta\left(-T+t_{1}\right)\right)+\frac{e^{\left(T+\frac{1}{\delta}\right) \lambda+\lambda\left(-T-\frac{1}{\delta}+t_{1}\right)} \lambda\left(-1+\delta\left(-T+t_{1}\right)\right)}{\left(-T-\frac{1}{\delta}+t_{1}\right)^{2}}+ \\
& \left.\frac{e^{\left(T+\frac{1}{\delta}\right) \lambda+\lambda\left(-T-\frac{1}{\delta}+t_{1}\right)} \lambda^{2}\left(-1+\delta\left(-T+t_{1}\right)\right)}{-T-\frac{1}{\delta}+t_{1}}\right) \\
& \frac{\partial T P_{\left(P, t_{1}, T\right)}}{\partial t_{1} \partial T}=\quad \frac{e^{\lambda t_{1}} p(a-b p)}{T^{2}}-\frac{C e^{t_{1}}}{\delta\left(-T-\frac{1}{\delta}+t_{1}\right)^{2}}+\frac{e^{t_{1}} p}{\delta\left(-T-\frac{1}{\delta}+t_{1}\right)^{2}}+\frac{e^{\left(T+\frac{1}{\delta}\right) \lambda+\lambda\left(-T-\frac{1}{\delta}+t_{1}\right)} o(a-b p)}{\delta\left(-T-\frac{1}{\delta}+t_{1}\right)^{2}} \\
& -\frac{(a-b p)^{2} s\left(-e^{\left(T+\frac{1}{\delta}\right) \lambda} \delta \lambda^{2} \operatorname{Ei}\left[\lambda\left(-T-\frac{1}{\delta}+t_{1}\right)\right]+\frac{2 e^{\left(T+\frac{1}{\delta}\right) \lambda+\lambda\left(-T-\frac{1}{\delta}+t_{1}\right)} \delta \lambda}{-T-\frac{1}{\delta}+t_{1}}-\frac{e^{\left(T+\frac{1}{\delta}\right) \lambda+\lambda\left(-T-\frac{1}{\delta}+t_{1}\right)} \lambda\left(-1+\delta\left(-T+t_{1}\right)\right)}{\left(-T-\frac{1}{\delta}+t_{1}\right)^{2}}\right)}{\delta^{2} \lambda}
\end{aligned}
$$

By assuming $\lambda<0,|\lambda|>\theta,|\lambda|>\delta, \quad b p<a \quad$ we $\quad$ have $\quad \frac{\partial^{2} T P\left(p, t_{1}, T\right)}{\partial t_{1}^{2}}<0, \frac{\partial^{2} T P\left(p, t_{1}, T\right)}{\partial T^{2}}<0$, $\frac{\partial^{2} T P\left(p, t_{1}, T\right)}{\partial T^{2}}>\frac{\partial^{2} T P\left(p, t_{1}, T\right)}{\partial t_{1} \partial T} \& \frac{\partial^{2} T P\left(p, t_{1}^{*}, T^{*}\right)}{\partial t_{1}^{* 2}}>\frac{\partial^{2} T P\left(p, t_{1}^{*}, T^{*}\right)}{\partial t_{1} \partial T}$

Using the example provided by Maihami and Nakhai (2012), we find the optimum value for $t_{1}^{*}$ and $T^{*}$, thus, the determinant of hessian matrix at the stationary point $\left(t_{1}^{*}, T^{*}\right)$ is:

$\operatorname{Det}(H)=\frac{\partial^{2} T P}{\partial t_{1}^{2}} \cdot \frac{\partial^{2} T P}{\partial T^{2}}-\left(\frac{\partial^{2} T P}{\partial t_{1} \partial T}\right)^{2}>0$

Hence, the Hessian matrix at point $\left(T^{*}, t_{1}^{*}\right)$ is negative definite and this completes the proof.

\section{References}

Abad, P. L. (1996). Optimal pricing and lot-sizing under conditions of perishability and partial backordering. Management Science, 42(8), 1093-1104.

Aggarwal, S. P., \& Jaggi, C. K. (1995). Ordering policies of deteriorating items under permissible delay in payments. Journal of the Operational Research Society, 46, 658-662.

Avinadav, T., Herbon, A., \& Spiegel, U. (2013). Optimal inventory policy for a perishable item with demand function sensitive to price and time. International Journal of Production Economics, 144(2), 497-506. 
Cai, G. G., Chiang, W. C., \& Chen, X. (2011). Game theoretic pricing and ordering decisions with partial lost sales in two-stage supply chains.International Journal of Production Economics, 130(2), 175-185.

Chew, P.EK., Lee. C., Liu, R., Hong, K.S., \& Zhang, A. (2014). Optimal dynamic pricing and ordering decisions for perishable products. International Journal of Production Economics, In press.

Chakrabarty, T., Giri, B. C., \& Chaudhuri, K. S. (1998). An EOQ model for items with Weibull distribution deterioration, shortages and trended demand: an extension of Philip's model. Computers \& Operations Research, 25(7), 649-657.

Chang, H. J., \& Dye, C. Y. (2001). An inventory model for deteriorating items with partial backlogging and permissible delay in payments. International Journal of Systems Science, 32(3), 345-352.

Chang, H. J., Hung, C. H., \& Dye, C. Y. (2002). A finite time horizon inventory model with deterioration and time-value of money under the conditions of permissible delay in payments. International Journal of Systems Science,33(2), 141-151.

Chang, H. J., Teng, J. T., Ouyang, L. Y., \& Dye, C. Y. (2006). Retailer's optimal pricing and lotsizing policies for deteriorating items with partial backlogging. European Journal of Operational Research, 168(1), 51-64.

Covert, R. P., \& Philip, G. C. (1973). An EOQ model for items with Weibull distribution deterioration. AIIE transactions, 5(4), 323-326.

Dye, C. Y., Ouyang, L. Y., \& Hsieh, T. P. (2007). Inventory and pricing strategies for deteriorating items with shortages: A discounted cash flow approach. Computers \& Industrial Engineering, 52(1), 29-40.

Geetha, K. V., \& Uthayakumar, R. (2010). Economic design of an inventory policy for noninstantaneous deteriorating items under permissible delay in payments. Journal of computational and applied mathematics, 233(10), 2492-2505.

Ghare, P. M., \& Schrader, G. F. (1963). A model for exponentially decaying inventory. Journal of Industrial Engineering, 14(5), 238-243.

Hwang, H., \& Shinn, S. W. (1997). Retailer's pricing and lot sizing policy for exponentially deteriorating products under the condition of permissible delay in payments. Computers \& Operations Research, 24(6), 539-547.

Jamal, A. M. M., Sarker, B. R., \& Wang, S. (1997). An ordering policy for deteriorating items with allowable shortage and permissible delay in payment. Journal of the Operational Research Society, 48, 826-833.

Misra, R.B. (1975). Optimum production lot size model for a system with deteriorating inventory, International Journal of production Research, 13(5), 495-505.

Mukhopadhyay, S., Mukherjee, R. N., \& Chaudhuri, K. S. (2004). Joint pricing and ordering policy for a deteriorating inventory. Computers \& Industrial Engineering, 47(4), 339-349.

Musa, A., \& Sani, B. (2012). Inventory ordering policies of delayed deteriorating items under permissible delay in payments. International Journal of Production Economics, 136(1), 75-83.

Maihami, R., \& Nakhai Kamalabadi, I. (2012). Joint pricing and inventory control for noninstantaneous deteriorating items with partial backlogging and time and price dependent demand. International Journal of Production Economics,136(1), 116-122.

Philip, G. C. (1974). A generalized EOQ model for items with Weibull distribution deterioration. AIIE Transactions, 6(2), 159-162.

Tadikamalla, P.R. (1978). An EOQ inventory model for items with Gamma distribution, AIIE Transactions 10, 108-112.

Wee, H.M. (1993). Economic production lot size model for deteriorating items with partial backordering. Computers and Industrial Engineering, 24(3), 449-458.

Wee, H. M. (1997). A replenishment policy for items with a price-dependent demand and a varying rate of deterioration. Production Planning \& Control, 8(5), 494-499. 